Artigo original

Hegemonia - Revista Eletrônica do Programa de Mestrado em Direitos Humanos, Cidadania e Violência/Ciência Política do Centro Universitário Unieuro

ISSN: 1809-1261

UNIEURO, Brasília, número 28, Julho a Dezembro de 2019, pp. 27-54.

Recebido em: 5/11/2018

Avaliado em: 13/12/2018

Aprovado em: 28/1/2019

\title{
EVOLUÇÃO DOS DIREITOS HUMANOS NO BRASIL: DA TEORIA À PRÁTICA
}

\author{
Ângelo Roberto Rosa Ávila ${ }^{1}$ e Vicente Fonseca ${ }^{2}$
}

\begin{abstract}
RESUMO: O reconhecimento dos abusos e arbitrariedades cometidas quando da eclosão e durante os conflitos mundiais ocorridos no início do século XIX que perduraram até sua primeira metade, e que importaram em práticas de incomparável violência e barbárie entre os diferentes povos, os Estados reconheceram a necessidade de criação de limites internacionais para preservação da espécie humana, e, bem assim, de que era necessária a elaboração de uma carta comum de direitos fundamentais, que, em um primeiro momento, privilegiassem a vida, a liberdade, a igualdade, e o direito de propriedade. Assim, surge a Declaração Universal dos Direitos Humanos, promulgada em 1948, trazendo direitos de caráter universal, indivisível e interdependentes. O Brasil, por sua vez, rompeu com o passado histórico de abuso, autoritarismo e arbitrariedade, promulgando a Constituição Federal de 1988, que se torna símbolo da cidadania e liberdade de expressão, sendo chamada de Carta Cidadã, pelo destaque dado à defesa de direitos fundamentais, traçados pela Declaração Universal de quarenta anos antes. Como signatário de todos os pactos internacionais que se relacionam ao tema, o Brasil torna-se precursor da consolidação democrática, inserindo os Direitos Humanos como programa de governo, editando, a partir de 1995, o Programa Nacional de Direitos Humanos, que atualmente está em sua terceira versão atualizada.
\end{abstract}

Palavras-chave: Direitos Humanos. Programa de governo. Consolidação democrática.

ABSTRACT: From the recognition of the abuses that occurred in world conflicts in the early nineteenth century which lasted until the first half, and they imported in practice unparalleled barbarity and violence among different peoples, States recognized the need to establish international limits for preservation the human species, and, as well, that it was necessary to elaborate a common charter of fundamental rights, which, at first, to favor the life, liberty, equality, and property rights. Thus arises the Universal Declaration of Human Rights, enacted in 1948, bringing rights universal, indivisible and interdependent. Brazil, in turn, broke with the history of abuse, authoritarianism and arbitrariness, promulgating the 1988 Constitution, which becomes a symbol of freedom of expression, being called the Citizen Charter, the emphasis given to the defense of fundamental rights set by the Universal Declaration of forty years before. As a signatory to all international agreements that relate to the topic, Brazil becomes the precursor of democratic consolidation, inserting Human Rights as a government program, editing, since 1995, the National Human Rights, which is currently in its third updated version.

Keywords: Human Rights. Government Program. Democratic Consolidation.

\footnotetext{
${ }^{1}$ Mestre em Ciência Política e Professor Titular da Secretaria de Estado de Educação do Distrito Federal.

${ }^{2}$ Doutor em Ciência Política e Professor do Centro Universitário Unieuro.
} 
Artigo original

Hegemonia - Revista Eletrônica do Programa de Mestrado em Direitos Humanos, Cidadania e Violência/Ciência Política do Centro Universitário Unieuro

ISSN: $1809-1261$

UNIEURO, Brasília, número 28, Julho a Dezembro de 2019, pp. 27-54.

\section{INTRODUÇÃO}

O presente artigo busca de forma precisa estudar a evolução dos direitos humanos no Brasil, a partir da análise das normas que operacionalizam a entronização desse tema no ordenamento jurídico nacional e bem assim na afirmação da democracia e construção da cidadania.

Para tanto, objetiva-se demonstrar que ao tempo em que o país avançou como nação precursora na criação de um programa de governo específico para tratar dos direitos humanos, na realidade, Estado e sociedade se encontram diante do fato de que apesar dessa classe de direitos estar amplamente institucionalizada, na realidade estão em contínua construção e afirmação.

A evolução dos direitos humanos no Brasil se confunde com a própria história do país e mesmo do mundo, de maneira que é possível observar que a partir do reconhecimento de atos de extrema violência praticada pelo Estado surgiram as lutas das minorias para ver reconhecido o direito que não é só de alguns, mas sim de uma espécie.

Esses direitos são universais, indivisíveis e complementares, e tornam-se fundamentais para conservação da raça humana e do estabelecimento de limites para ação do Estado em face do cidadão.

A Declaração Universal dos Direitos Humanos surge como conquista sem precedentes, a partir da memória recente das duas grandes guerras mundiais que a pouco haviam sido enfrentadas, e que se caracterizaram por ações de grande violência, com práticas de extermínio e incontáveis atrocidades. Daí, necessário se fez a mobilização dos indivíduos em favor dos direitos humanos, fazendo com que surgissem preocupações efetivas de todas as Nações com o futuro da humanidade.

Os direitos humanos são editados, pois, para todos os seres humanos, em especial para as minorias e para coibir a arbitrariedade do Estado, afirmando-se a soberania.

No Brasil, o grande marco normativo de internalização dos direitos humanos se faz na Constituição Federal de 1988, que em especial trouxe preceitos fundamentais de garantia a vida, a liberdade, a igualdade, a segurança, e a propriedade.

Na sequência, criou-se a Secretaria Nacional de Direitos Humanos, e com o apoio multiprofissional e de representação de toda a sociedade civil, traçaram-se os eixos e metas do 
Artigo original

Hegemonia - Revista Eletrônica do Programa de Mestrado em Direitos Humanos, Cidadania e Violência/Ciência Política do Centro Universitário Unieuro

ISSN: 1809-1261

UNIEURO, Brasília, número 28, Julho a Dezembro de 2019, pp. 27-54.

primeiro Programa Nacional de Direitos Humanos - PNDH, que é inovador no estabelecimento de compromissos de atenção às minorias e combate a toda forma de discriminação, nelas incluídas: crianças, adolescentes, mulheres, trabalhadores, despossuídos, índios, negros, pessoas com deficiência, pessoas com diversidade de orientação sexual, dentre outras.

Desta forma, é importante reforçar que o PNDH constrói suas metas no mesmo ritmo em que avança a sociedade e possui seu dinamismo, de maneira que já passou por duas atualizações desde a primeira versão erigida em 1995.

Esse processo de revisão também é importante marco na promoção e proteção dos direitos humanos, pois desde a IV Conferência Nacional de Direitos Humanos, realizada em 1999, na Câmara dos Deputados, em Brasília, elevou os direitos econômicos, sociais e culturais ao mesmo patamar de importância dos direitos civis e políticos, atendendo a reivindicação da sociedade civil.

\section{A EVOLUÇÃO DOS DIREITOS HUMANOS NO BRASIL}

Tratar do tema Direitos Humanos no Brasil perpassa não somente pela necessária, ainda que breve digressão histórica acerca de sua internalização, mas especialmente pelo reconhecimento de tratar-se de um direito inerente à raça humana, e bem assim pela percepção de que a conquista desses direitos advém da luta e da resistência imprimidas pelas minorias, visando alcançar direitos fundamentais básicos do ser humano, em face de anos marcantes de subjugação e extrema violência do Estado.

Como ressalta Paulo César Carbonari, "fazer uma leitura da situação dos direitos humanos no Brasil é um exercício complexo e difícil” e nos remete à compreensão de que:

O núcleo dos direitos humanos radica-se na construção de reconhecimento, e como tal constitui um processo de criação de condições de interação e de multidimensionalização das relações do humano, o meio e as utopias. Afirma-se por meio da luta permanente contra a exploração, o domínio, a vitimização, a exclusão e todas as formas de apequenamento do humano. É luta permanente pela emancipação e pela construção de relações solidárias e justas. Por isso, a afirmação dos direitos humanos sempre esteve - e continua - profundamente imbricado às lutas libertárias construídas ao longo dos séculos pelos(as) 
Artigo original

Hegemonia - Revista Eletrônica do Programa de Mestrado em Direitos Humanos, Cidadania e Violência/Ciência Política do Centro Universitário Unieuro

ISSN: $1809-1261$

UNIEURO, Brasília, número 28, Julho a Dezembro de 2019, pp. 27-54.

oprimidos(as) e vitimados(as) para abrir caminhos e construir pontes de maior humanidade. Isso porque a realização dos direitos humanos é um processo histórico, assim como é histórico seu conteúdo. (2003, p. 18)

Ao mesmo tempo, vive-se uma constante afirmação e construção dos pilares desses direitos universais, já que o entendimento primário de sua aplicação, sob a ótica da sociedade aparentemente desfavorecida, se dá, de forma ambígua, isto é, não raro, na compreensão desses direitos serem aplicados somente em favor de criminosos e meliantes em geral, no ato de sua prisão ou cumprimento de pena, caracterizando uma dicotomia grosseira pelo contraste entre a teoria e a prática.

A Declaração Universal de 1948 inovou na tratativa dos direitos humanos, trazendo uma concepção bastante contemporânea, fundamentada na universalidade, indivisibilidade e complementariedade desses direitos. São universais em razão de sua extensão alcançar a integralidade da raça humana, como um evidente direito de espécie. São indivisíveis uma vez que une os direitos civis e políticos aos direitos econômicos, sociais e culturais, antes vistos como tratados distintos e autônomos. A partir daí tornam-se, ainda, interdependentes, complementares.

Destaca Carbonari, que a formação da sociedade brasileira se deu, em regra, pela exclusão de grande parte da população, na absoluta contramão dos Direitos Humanos, o que impediu, em um primeiro momento, a edificação de direitos universais diante da prática da discriminação, sendo que:

As marcas estão fundamentalmente em três questões: a pobreza e desigualdade; o racismo; e o sexismo. A pobreza é marca estrutural e persistência histórica em consequência das opções de desenvolvimento que, em regra, têm privilegiado setores (elites) econômicos. Donatários de capitanias hereditárias, senhores de engenho, donos de minas, fazendeiros, donos da indústria e de bancos, sucessivamente, têm orientado de forma prioritária a dinâmica do desenvolvimento, sempre pautada por seus próprios interesses e pela subserviência aos ditames coloniais (ou colonialistas, mais recentemente imperialistas) de cada época. Escravos, trabalhadores do campo, imigrantes pobres e trabalhadores urbanos têm sido os que historicamente ficaram alijados do acesso aos bens e à riqueza do País. A concentração da renda e da riqueza e a consequente 
Artigo original

Hegemonia - Revista Eletrônica do Programa de Mestrado em Direitos Humanos, Cidadania e Violência/Ciência Política do Centro Universitário Unieuro

ISSN: $1809-1261$

UNIEURO, Brasília, número 28, Julho a Dezembro de 2019, pp. 27-54.

desigualdade estrutural são marcas históricas da formação social e econômica, sem que o Estado, via de regra, em suas diversas versões históricas, tenha consegui- do ultrapassar seu enfrentamento como caso de polícia ou com ações populistas ou compensatórias. (2003, p. 21)

$\mathrm{Na}$ atualidade, nota-se que os direitos humanos estão institucionalizados no Brasil, mas sua aplicação ainda está em construção, necessitando de afirmação diária desses direitos como fundamentais da espécie.

Como bem salienta Maria Victoria Benevides, apesar dos direitos humanos serem a afirmação da democracia no chamado mundo desenvolvido, e substancialmente integrarem o elenco de valores de um povo, e com isso, ser obrigatória a sua incorporação à vida política, observa-se justamente o oposto, ou seja:

É justamente nos países que mais violam os direitos humanos, nas sociedades que são mais marcadas pela discriminação, pelo preconceito e pelas mais variadas formas de racismo e intolerância, que a ideia de direitos humanos permanece ambígua e deturpada.

Analisando as possibilidades que criam a concepção ambígua e percepção equivocada de uma sociedade quanto ao alcance dos direitos humanos, tem-se que isso se dá em razão de que estes direitos foram direcionados às minorias, atingidas pela opressão política, pela violência, as prisões ilegais e abusivas, a tortura, o exílio, e os assassinatos.

A propósito, colhe-se a irretocável lição do Prof. Celso D. De Albuquerque Mello, ao dizer que: "O direito, seja ele qual for, dirige-se sempre aos homens. O homem é a finalidade última do Direito. Este somente existe para regulamentar a vida entre os homens.” (1999, p. 102)

Para Antônio Augusto Cançado Trindade, a proteção internacional dos Direitos Humanos, a partir de uma análise histórica, superou barreiras do passado, asseverando que:

Compreendeu-se, pouco a pouco, que a proteção dos direitos básicos da pessoa humana não se esgota, como não poderia esgotar-se, na atuação do Estado, na pretensa e indemonstrável 'competência nacional exclusiva'. Esta última (equiparável ao chamado 'domínio reservado do Estado') afigura-se como um reflexo, manifestação ou particularização da própria 
Artigo original

Hegemonia - Revista Eletrônica do Programa de Mestrado em Direitos Humanos, Cidadania e Violência/Ciência Política do Centro Universitário Unieuro

ISSN: 1809-1261

UNIEURO, Brasília, número 28, Julho a Dezembro de 2019, pp. 27-54.

noção de soberania, inteiramente inadequada ao plano das relações internacionais, porquanto originalmente concebida, tendo em mente o Estado in abstracto (e não em suas relações com outros Estados), e, como expressão de um poder interno, de uma supremacia própria de um ordenamento de subordinação claramente distinto do ordenamento internacional, de coordenação e cooperação, em que todos os Estados são, ademais de independentes, juridicamente iguais". (apud ROCHA, 1999, p.102)

\section{INTERNALIZAÇÃO DOS DIREITOS HUMANOS NO BRASIL}

Toda prática de violência do Estado brasileiro é injustificada e arbitrária, especialmente comum à década de sessenta, e a memória recente das duas grandes guerras mundiais que a pouco haviam sido enfrentadas, incentivaram a mobilização dos indivíduos em favor dos direitos humanos, fazendo com que, nos anos setenta, as primeiras comissões de direitos humanos fossem criadas, e bem assim tratados os temas: tortura, desaparecimento de dissidentes e presos políticos no período de ditadura e o sistema prisional.

Neste primeiro momento, não havia dúvida de que os direitos humanos foram editados para as minorias e para o combate da arbitrariedade e peso excessivo da mão do Estado, que estava influenciado pelo poder absoluto sobre os indivíduos e, também, pela histórica exclusão da maior parcela da população na formação da sociedade, na medida em que havia discriminação explícita em razão do sexo, da raça, e da condição econômica e social.

Neste contexto surge a Constituição Federal de 1988 como o grande marco da entronização dos fundamentos dos Direitos Humanos no ordenamento jurídico nacional, com a feição estabelecida na Declaração Universal de quatro décadas antes, acabando por receber a denominação de Carta Cidadã.

O traçado da Constituição está em total harmonia ao disposto na Declaração de 1948, no que se refere, por exemplo, aos seguintes direitos fundamentais, de caráter universal:

Todas as pessoas nascem livres e iguais em dignidade e direitos. Toda pessoa tem direito à vida, à liberdade e à segurança pessoal. Todos são 
Artigo original

Hegemonia - Revista Eletrônica do Programa de Mestrado em Direitos Humanos, Cidadania e Violência/Ciência Política do Centro Universitário Unieuro

ISSN: 1809-1261

UNIEURO, Brasília, número 28, Julho a Dezembro de 2019, pp. 27-54.

iguais perante a lei e tem direito, sem qualquer distinção, a igual proteção da lei.

Nesse contexto, a Carta Cidadã, como instrumento da consolidação democrática, trouxe em seu artigo $5^{\circ}$, os fundamentos básicos da sociedade brasileira, edificada em base sólida para garantia da vida, da igualdade, da liberdade, da segurança e da propriedade:

Todos são iguais perante a lei, sem distinção de qualquer natureza, garantindo-se aos brasileiros e aos estrangeiros residentes no País a inviolabilidade do direito à vida, à liberdade, à igualdade, à segurança e à propriedade.

As crianças e os adolescentes passaram a ser especialmente reconhecidos como sujeitos de direito, e com isso, protegidos pelo Estado, que introduziu na dialética jurídica os fundamentos da proteção integral e da prioridade absoluta, havendo previsão Constitucional expressa nesse sentido, erigida em seu artigo 227, o que, pouco tempo depois, impulsionou a edição do Estatuto da Criança e do Adolescente.

Em 1993, realizou-se a II Conferência Mundial de Direitos Humanos, momento marcante em que foram firmados compromissos de adoção, pelos Estados, de programas de ação efetivos, voltados ao favorecimento e efetivação dos direitos fundamentais e universais dos seres humanos.

Aduz Gérard Peytrignet, Ex-Chefe da Delegação Regional do Comitê Internacional da Cruz Vermelha no Brasil, ao tratar da força dos tratados internacionais firmados pelos Estados partícipes, como compromisso de humanidade, não só tem o dever de respeitar as normas neles contidas, mas especialmente de fazê-las respeitar:

Em primeiro lugar, as normas do DIH são de índole "imperativa” (“jus cogens"), e não meramente dispositivas. Cabe mencionar, neste âmbito, que as convenções de Genebra de 1949 constituem, hoje em dia, a maior comunidade convencional conhecida, com um total de 177 EstadosPartes, o que a torna verdadeiramente universal.

Em segundo lugar, os altos valores que inspiram o DIH, converteram os seus preceitos em compromissos absolutos de humanidade, deixando 
Artigo original

Hegemonia - Revista Eletrônica do Programa de Mestrado em Direitos Humanos, Cidadania e Violência/Ciência Política do Centro Universitário Unieuro

ISSN: $1809-1261$

UNIEURO, Brasília, número 28, Julho a Dezembro de 2019, pp. 27-54.

então de ser tratados de correspondência mútua e limitados. Por este motivo, o conjunto dos Estados-Partes nas Convenções de Genebra, e de acordo com o seu Art. $1^{\circ}$, não só tem a obrigação de respeitar as suas normas, mas também de fazê-las respeitar, em qualquer situação, embora elas não estejam diretamente envolvidas nas referidas contendas armadas! Em terceiro lugar, essas Convenções não são sujeitas à condição de reciprocidade, o que implica que a não-aplicação por um Estado-Parte dos seus deveres não permite que o adversário se desvincule dos seus. Não se trata, então, de um intercâmbio equitativo de prestações, mas de obrigações de caráter superior inderrogáveis. (apud ROCHA, 1999, p. 94)

Assim, de forma convergente com o que mundialmente se construía com base nos preceitos de Direitos Humanos, o Brasil passou a discutir de forma efetiva a elaboração de normas internas que institucionalizassem os compromissos firmados internacionalmente.

E nesse sentido, como assevera Antônio Augusto Caçado Trindade, a implementação internacional dos direitos humanos depende, em última análise, do funcionamento eficaz dos órgãos de proteção internos dos Estados de modo que:

No domínio da proteção dos direitos humanos, interagem o direito internacional e o direito interno movido pelas mesmas necessidades de proteção, prevalecendo as normas que melhor protejam o ser humano. A primazia é da pessoa humana. (apud ROCHA, 1999, p. 94)

\section{ANÁLISE RETROSPECTIVA DO PROGRAMA NACIONAL DE DIREITOS HUMANOS}

No primeiro governo de Fernando Henrique Cardoso, com o início dos trabalhos de elaboração da versão original do Programa Nacional de Direitos Humanos - PNDH, o Brasil passou a ser o primeiro país a tratar os direitos humanos como política de governo, em 1995, atendendo recomendação específica da Conferência Mundial de Direitos Humanos (Viena, 1993).

Neste primeiro momento, o PNDH, que é organizado em eixos e metas, atribuiu maior destaque aos direitos civis, pelo reconhecimento de que estão diretamente ligados à integridade 
Artigo original

Hegemonia - Revista Eletrônica do Programa de Mestrado em Direitos Humanos, Cidadania e Violência/Ciência Política do Centro Universitário Unieuro

ISSN: 1809-1261

UNIEURO, Brasília, número 28, Julho a Dezembro de 2019, pp. 27-54.

física e ao espaço de cidadania de cada indivíduo. Entretanto, é certo que apesar de suas três gerações serem indivisíveis, ou seja - a dos direitos civis e políticos, a dos direitos sociais, econômicos e culturais, e a dos direitos coletivos - isso não desqualifica, num primeiro momento, a adoção de políticas específicas que se iniciam pela garantia e efetivação dos direitos civis, com perspectiva de contemplar, na sequência, as outras dimensões.

Tanto foi assim, que uma das principais medidas adotadas, antes mesmo da formulação do que posteriormente seria o Programa Nacional de Direitos Humanos, foi criada a Comissão Permanente de Direitos Humanos na Câmara Federal, sob a coordenação do então deputado Nilmário Miranda, ex-preso político, foi promulgada a Lei 9.140, de 01/12/1995 e criada, no Ministério da Justiça, a Comissão de Mortos e Desaparecidos Políticos.

Por esta lei, o Governo reconhece a morte de "pessoas desaparecidas em razão de participação ou acusação de participação em atividades políticas no período de 2 de setembro de 1961 a 15 de agosto de 1979”, período este que, posteriormente, foi ampliado até 5/10/1988, para reconhecimento de desaparecidos (Lei 10.536, 14/08/2002).

Pouco tempo depois, houve a transferência da justiça militar para a justiça comum da apuração e julgamento dos crimes dolosos contra a vida praticados por policiais militares, editada pela Lei 9.299/96. Esta lei permitiu o indiciamento e julgamento de policiais militares em casos de múltiplas e graves violações como os do Carandiru, Corumbiara e Eldorado dos Carajás. $\mathrm{Na}$ sequência, veio, ainda, a tipificação do crime de tortura, Lei 9.455/97, que constituiu marco referencial para o combate a essa prática criminosa no Brasil.

O PNDH 1 é considerado o precursor da entronização de políticas públicas especificamente voltadas ao reconhecimento dos direitos humanos como direito de espécie, e é exemplo de construção baseada na reunião de equipes multiprofissionais, por meio da realização de discussões específicas aos temas das minorias e omissões que permeavam o ordenamento jurídico, por meio de seminários regionais, consultas a um largo espectro de centros de direitos humanos e personalidades.

Ele parte de premissas básicas para promoção dos direitos humanos, equacionando problemas estruturais recorrentes, como aqueles provocados pelo desemprego, violência, fome, dificuldades do acesso à terra, à saúde, à educação, a concentração de renda, o sexismo e a intolerância. 
Artigo original

Hegemonia - Revista Eletrônica do Programa de Mestrado em Direitos Humanos, Cidadania e Violência/Ciência Política do Centro Universitário Unieuro

ISSN: 1809-1261

UNIEURO, Brasília, número 28, Julho a Dezembro de 2019, pp. 27-54.

Em seus eixos, foram abordados os entraves à cidadania plena, que levam à violação sistemática dos direitos, visando a proteção do direito à vida e à integridade física; o direito à liberdade; o direito à igualdade perante à lei.

Após discussões incansáveis, em fevereiro de 1996, o projeto do PNDH 1 foi apresentado e debatido na I Conferência Nacional de Direitos Humanos, promovida pela Comissão de Direitos Humanos da Câmara de Deputados, com o apoio do Fórum das Comissões Legislativas de Direitos Humanos, Comissão de Direitos Humanos da OAB Federal, Movimento Nacional de Direitos Humanos, CNBB, FENAJ, INESC, SERPAJ e CIMI, em abril de 1996.

Como se observa, no processo de elaboração do primeiro PNDH foi colocada em prática a parceria entre o Estado e as organizações da sociedade civil, bem como consultados organismos internacionais que tratavam especificamente da questão dos direitos humanos, intensificando-se esta parceria, em seguida, na execução do programa.

Isto parte do reconhecimento de que os Direitos Humanos, para alcançarem sua efetiva importância e lastro dentro da sociedade, devem ser tratados como comprometimento coletivo, alcançando não só o Estado, mas todos os indivíduos, assumindo um papel ativo para a consecução e efetivação dos objetivos do programa.

Nesse sentido, o PNDH 1 contempla um largo elenco de medidas na área de direitos civis, com consequências diretas e decisivas para a proteção dos direitos sociais, econômicos e culturais, tais como a implementação das convenções internacionais dos direitos das crianças, das mulheres e dos trabalhadores.

Várias e efetivas foram as conquistas trazidas pelo PNDH 1, das quais podem ser destacadas:

$-1997$

-A Criação da Secretaria Nacional de Direitos Humanos, no Ministério da Justiça. Seu primeiro secretário é José Gregori.

- A promulgação da Lei 9.140/95,

- A promulgação da Lei 9.455/97 define e pune o crime de tortura como um tipo penal autônomo e específico.

- A promulgação da Lei no 9.474, de 22/7/97, regulamenta o Estatuto do Refugiado no Brasil, de acordo com a Convenção de Genebra.

-A Criação do Comitê Nacional para os Refugiados CONARE. 
Artigo original

Hegemonia - Revista Eletrônica do Programa de Mestrado em Direitos Humanos, Cidadania e Violência/Ciência Política do Centro Universitário Unieuro

ISSN: $1809-1261$

UNIEURO, Brasília, número 28, Julho a Dezembro de 2019, pp. 27-54.

- 1999 - edição do Decreto n 3.298 de 20/12/99, que define as competências do Conselho Nacional dos Direitos das Pessoas Portadoras de Deficiências (CONADE).

Decorridos aproximadamente seis anos do lançamento do Programa Nacional de Direitos Humanos - PNDH 1, teve início sua atualização, realizada a partir da análise dos resultados alcançados e bem assim, do levantamento da vantagem de sistematização das demandas da sociedade, avançou o Brasil, com isso, mais uma significativa etapa na promoção e proteção dos direitos humanos.

O período do PNDH 2, iniciado em meados de 2001, incorpora ações específicas no campo da garantia do direito à educação, à saúde, à previdência e assistência social, ao trabalho, à moradia, a um meio ambiente saudável, à alimentação, à cultura e ao lazer, e é marcado por mais conquistas, dentre as quais são destacadas:

- 2002 - Edição o Decreto n 4.377, de 13/9/2002, que trata sobre a Eliminação de Todas as Formas de Discriminação contra a Mulher.

- 2005 - Unificação dos programas sociais de renda mínima no Brasil

- 2011 - Criação da Comissão Nacional da Verdade, pela Lei 12528/2011 e instituição em 16 de maio de 2012 - apurar graves violações de Direitos Humanos entre 18/09/1946 a 5/10/1988.

Nesta esteira, foram sendo identificados os problemas estruturais e as demandas sociais, e a partir disso, erigidas alternativas para a solução de questões antigas que afrontavam os preceitos de direitos humanos.

Tais estudos serviram, em mínima análise, como instrumento de formulação e implementação de políticas públicas e criação de programas específicos de governos, em todas as esferas, sob a ótica da promoção e garantia dos direitos humanos.

Sem precedentes na história do país, a criação da Secretaria de Estado dos Direitos Humanos, possibilitou o engajamento efetivo do Governo Federal em ações voltadas para as minorias, a afronta aos Direitos Humanos, de maneira que as metas do PNDH 1 e 2 foram, em sua maioria, sendo incorporadas aos instrumentos de planejamento e orçamento do Governo 
Artigo original

Hegemonia - Revista Eletrônica do Programa de Mestrado em Direitos Humanos, Cidadania e Violência/Ciência Política do Centro Universitário Unieuro

ISSN: 1809-1261

UNIEURO, Brasília, número 28, Julho a Dezembro de 2019, pp. 27-54.

Federal, com recursos financeiros assegurados nas Leis Orçamentárias Anuais, conforme determina o Plano Plurianual (PPA).

Houve, neste período, a construção da proposta de reforma do Poder Judiciário, na qual se inclui, entre outras medidas destinadas a agilizar o processamento dos responsáveis por violações, a chamada 'federalização' dos crimes de direitos humanos.

A partir destas conquistas e do efetivo trabalho para entronização das bases fundamentais dos direitos humanos no Brasil, o país recebeu várias visitas dos relatores da ONU sobre os temas da venda de crianças, prostituição e pornografia infantis; da violência contra a mulher; do racismo, discriminação racial, xenofobia e intolerância correlata; dos direitos humanos e resíduos tóxicos; tortura e, mais recentemente, sobre o direito à alimentação.

\section{OS DIREITOS HUMANOS NA GESTÃO DO PRESIDENTE LULA E AS CONQUISTAS PARA A SOCIEDADE BRASILEIRA}

Fazendo uma análise retrospectiva, é importante mostrar que o início da caminhada direto aos Direitos Humanos no Brasil, começa com a constituição de 1988, onde podemos perceber nos Arts. $5^{\circ}, 6^{\circ}$ e $7^{\circ}$ e seus itens, as proteções vinculadas as leis de Estado para com os cidadãos brasileiros. Esse avanço vem da gestão presidencial de Fernando Henrique Cardoso, onde se dá a elaboração dos eixos orientadores, diretrizes, objetivos estratégicos e suas ações programáticas para a formulação do primeiro Programa Nacional dos Direitos Humanos - PNDH.

Os PNDHs foram sendo aprimorados a cada ano e chegou até o PNDH-3 sendo aperfeiçoado em suas linhas de pensamento voltadas para a dignidade e respeito ao cidadão brasileiro. É justamente na política de governo do presidente Luiz Inácio Lula da Silva que essas linhas de pensamento, se encorpam e tomam formas. Foi pensando nos artigos da Constituição de 1988, que a equipe e elaboradores desses eixos dentro do governo Lula, começa então reestruturar as diretrizes dos PNDHs 1 e 2, para se consolidar com a assinatura do decreto presidencial do PNDH-3.

O PNDH-3 representa um verdadeiro roteiro para seguirmos consolidando os alicerces desse edifício democrático, diz o presidente Lula, e continua: 
Artigo original

Hegemonia - Revista Eletrônica do Programa de Mestrado em Direitos Humanos, Cidadania e Violência/Ciência Política do Centro Universitário Unieuro

ISSN: 1809-1261

UNIEURO, Brasília, número 28, Julho a Dezembro de 2019, pp. 27-54.

Diálogo permanente entre o Estado e a sociedade civil; transparência em todas esferas de governo; primazia dos Direitos Humanos nas políticas internas e nas relações internacionais; caráter laico do Estado; fortalecimento do pacto federativo; universalidade, indivisibilidade e interdependência dos civis, políticos, econômicos, sociais, culturais e ambientais; opção clara pelo desenvolvimento sustentável; respeito a diversidade; combate as desigualdades; erradicação da fome e da extrema pobreza.(PNDH-3,pag11)

$\mathrm{Na}$ época o governo Lula apresentava 31 ministérios e o fato inédito que ocorreu naquele momento, foi a participação administrativa desses ministérios dentro das políticas públicas do Governo Federal para o aprimoramento da última edição do PNDH-3.

Em janeiro de 2008, no Rio de Janeiro, durante um cerimonial em homenagem aos mortos do Holocausto e de Auschewitz ${ }^{2}$, o presidente convoca uma ampla jornada de discussões, debates e seminários para utilizar o PNDH que o Brasil já possuía desde 1996, com uma importante ampliação em 2002. Tratava-se de revisar o programa, assimilando demandas crescentes da sociedade e incorporando os elementos dos tratados internacionais mais recentes, seja do sistema ONU, seja da OEA. Cumprindo-se a agenda intensa com essa finalidade, em todo o País, culminando com a realização da $11^{\mathrm{a}}$ Conferência Nacional dos Direitos Humanos, que reuniu em Brasília cerca de 1.200 delegados e 800 convidados e observadores.

No início do governo Lula dá se a transformação da Secretaria especial dos Direitos Humanos em ministério e ao mesmo tempo foi criada a Secretaria Especial de Políticas e Promoção da Igualdade Racial e a Secretaria Especial de Políticas para as Mulheres, também com força de ministério. Com essa atitude, o governo torna proteção aos Direito Humanos concebida como ação integrada, e mais, como verdadeira política de Estado, impedindo que ocorram interferências quando houver alternância de partidos no poder.

Ainda podemos falar a respeito da política econômica e nos exercícios orçamentários, onde foi feito grande esforço para assegurar aos brasileiros o mais elementar entre todos os Direitos Humanos, que é a alimentação garantida a todas as famílias pobres. Tendo visto que, a fome ainda

\footnotetext{
${ }^{2}$ Nome de uma rede de campos de concentração localizados no sul da Polônia operados pelo Terceiro Reich nas áreas polonesas anexadas pela Alemanha Nazista, maior símbolo do Holocausto perpetrado pelo nazismo durante a Segunda Guerra Mundial.
} 
Artigo original

Hegemonia - Revista Eletrônica do Programa de Mestrado em Direitos Humanos, Cidadania e Violência/Ciência Política do Centro Universitário Unieuro

ISSN: 1809-1261

UNIEURO, Brasília, número 28, Julho a Dezembro de 2019, pp. 27-54.

não foi erradicada, mas já podemos saudar a retirada de 19 milhões de pessoas da extrema pobreza, alcançando assim, a meta da ONU em reduzir esses números pela metade até 2015.

$\mathrm{Na} 8^{a}$ Conferência Nacional dos Direitos da Criança e do Adolescente, foi elaborado um plano decenal para esse segmento. Foram avaliados a implantação do chamado Sistema Nacional do Atendimento Socioeducativo, a nova lei de adoção e o Plano Nacional de Garantia do Direito à Convivência Familiar e Comunitária. Também organizou em 2008 o maior congresso mundial sobre o combate a exploração sexual de crianças, 3.500 participante de 170 países.

Nos anos em que seguiam o seu governo, cresciam e se aperfeiçoavam os programas de proteção aos defensores dos Diretos Humanos, as vítimas e testemunhas ameaçadas e aos adolescentes sob risco de morte. O combate à tortura e o enfrentamento das modalidades recentes de trabalho escravo e o empenho para erradicar o sub-registro civil de nascimento.

Pensando no futuro das crianças, adolescentes e jovens foi feita uma parceria importante em dois órgãos do governo, entre a Secretaria Especial de Direitos Humanos - SEDH e o Ministério da Educação - MEC para priorizar nos anos seguintes, ou seja, no próximo decênio o Plano Nacional de Educação em Direitos Humanos - PNEDH, uma estratégia do governo para transformar o Brasil num país onde, de fato todos assimilem os segmentos de solidariedade e respeito à pessoa humana.

Em relação as pessoas com deficiência, ou seja, especiais, o Brasil é um dos países mais inclusivos das Américas, tanto pela legislação avançada como pelo conjunto das políticas públicas dirigidas a essa população. Naquele momento, uma das maiores conquistas nessa área foi a ratificação da Convenção da ONU sobre os Direitos das Pessoas com Deficiência, sendo incorporada a nossa legislação com equivalência de emenda constitucional. Hoje podemos notar alguns avanços dentro dessa área tais como transportes urbanos com lugares para deficientes e rampas de acesso, rebaixamento de calçadas, lugares preferenciais nas filas, cadeiras preferenciais em estádio, ginásios e teatros, descontos em ingressos, vagas especiais em concursos públicos.

Também podemos citar o avanço e aprovação no Estatuto do Idoso, consolidando diferentes normas de proteção aos milhões de idosos brasileiros. Não se pode deixar de colocar um momento muito importante dentro de seu mandato, que foi a realização do $1^{\mathrm{a}}$ Conferência Nacional de Gays, Lésbicas, Bissexuais, Travestis e Transexuais, em 2008, para construir um país 
Artigo original

Hegemonia - Revista Eletrônica do Programa de Mestrado em Direitos Humanos, Cidadania e Violência/Ciência Política do Centro Universitário Unieuro

ISSN: 1809-1261

UNIEURO, Brasília, número 28, Julho a Dezembro de 2019, pp. 27-54.

sem qualquer tipo de intolerância homofóbica ${ }^{3}$. A Lei Maria da Penha entrou como um marco histórico no enfrentamento da violência contra a mulher.

Reconhecendo o direito de morar dignamente como um direito humano, em 2005 foi criado o Fundo Nacional de Habitação de Interesse Social - FNHIS, e no governo Lula, em 2009 foi lançado o programa Minha Casa, Minha Vida visando construir um milhão e moradia nos anos que gestão governamental e demais anos. Juntamente a esses programas, teve um muito importante em relação a questão da pobreza, o programa Territórios da Cidadania, em regiões com indicadores sociais mais problemáticos, o programa vem reunir 1.800 municípios para unificar distintas ações de combate à pobreza, ao mesmo tempo em que fortalece a agricultura familiar e projetos de reforma agrária.

Ainda dentro de seu mandato, o presidente Lula, levanta a questão dos mortos e desaparecidos políticos do período ditatorial e o PNDH-3 dá um passo importante no sentido de criar uma Comissão nacional da Verdade, com a tarefa de promover esclarecimento público das violações de Direitos Humanos por agentes do Estado na repressão aos opositores.

Em frases finais o presidente Lula coloca que nesse PNDH-3 será um roteiro consistente e seguro para seguir consolidando a marcha histórica que resgata nosso país de seu passado escravista, subalterno, elitista e excludente, no rumo da construção d uma sociedade crescentemente assentada nos grandes ideais humanos de liberdade, igualdade e da fraternidade.

O que tem a Dizer o Ministro da Secretaria Especial dos Direitos Humanos da Presidência da República - MSEDHPR

Com a criação do Ministério da Secretaria Especial dos Direitos Humanos da Presidência da República, Paulo Vannuchi dá inicialmente uma breve definição do que seria os Direitos Humanos para o cidadão brasileiro. Ele Coloca que:

...toda pessoa tem direitos inerentes à sua natureza humana, sendo respeitada sua dignidade e garantida a oportunidade de desenvolver seu potencial de forma livre, autônoma e plena. Dessa forma os princípios históricos dos Direitos Humanos são orientados pela afirmação do respeito ao outro e pela busca permanente da paz. Paz que, em qualquer

\footnotetext{
${ }^{3}$ É uma série de atitudes e sentimentos negativos em relação a pessoas homossexuais, bissexuais e, em alguns casos, outras transgêneros e pessoas intersexuais.
} 
Artigo original

Hegemonia - Revista Eletrônica do Programa de Mestrado em Direitos Humanos, Cidadania e Violência/Ciência Política do Centro Universitário Unieuro

ISSN: 1809-1261

UNIEURO, Brasília, número 28, Julho a Dezembro de 2019, pp. 27-54.

contexto, sempre tem seus fundamentos na justiça, na igualdade e na liberdade. (PNDH-3, pág.15)

A agenda dos Direitos Humanos veio possibilitar aos brasileiros, principalmente os dos setores populares organizados fincar um marco de suas lutas em diferentes senários, buscando nos anos passados a resistência a ditadura, e hoje, para exigir a efetivação de relações sociais igualitárias e justas. Dessa forma podemos ver os Direitos Humanos se fortalecendo e erguendo como bandeira a democratização permanente do Estado e da própria sociedade. É desses movimentos que o Estado vem colhendo demandas e exigências para incorporá-la em suas ações programáticas nas diferentes políticas públicas.

A Declaração Universal dos Direitos Humanos, lançada em 10 de dezembro de 1948, fundou os alicerces de uma nova convivência humana, a partir dela vieram os diversos pactos, tratados e convenções internacionais que construíram passo a passo a base para a proteção mundial dos Direitos Humanos. Em 1993 vem a Conferência de Viena, da ONU, onde estabelece os postulados de universalidade, indivisibilidade e interdependência, e essa universalidade estabelece a única condição de existir como ser humano é requisito único para titularidade desses direitos. Para a individualidade está ligada diretamente aos direitos econômicos, sociais e culturais e se torna indivisível sempre que um direito é violado, se quebra a unidade e todos os demais direitos são comprometidos.

A partir da Conferência de Viena, o Brasil redemocratizado, ratificou os principais instrumentos internacionais de direitos Humanos, tornando assim parte do ordenamento nacional. A Carta Constitucional inclui entre os fundamentos do Estado brasileiro a cidadania e a dignidade de pessoa humana, estabelecendo como objetivo primordial a construção de uma sociedade, livre, justa e solidária e ao mesmo tempo envolvendo todas as condições favoráveis de qualidade de vida a todos os cidadãos da nação brasileira, obrigando assim também ao país a reger suas relações internacionais pela prevalência dos Direitos Humanos.

Tendo formulado esse documento o Brasil agora passa a organizar seus pensamentos voltados para os interesses democráticos de seu povo. Com a vivência de sua história, pôde então, começar a redigir as diretrizes nacionais que orientam a atuação do poder público no âmbito dos Direitos Humanos. Esse processo ocorreu em 1996 com o lançamento do primeiro Programa Nacional de Direitos Humanos - PNDH-1. Seis anos depois o programa foi revisado e atualizado em 2002, sendo ampliado com a incorporação dos direitos econômicos, sociais e culturais, 
Artigo original

Hegemonia - Revista Eletrônica do Programa de Mestrado em Direitos Humanos, Cidadania e Violência/Ciência Política do Centro Universitário Unieuro

ISSN: 1809-1261

UNIEURO, Brasília, número 28, Julho a Dezembro de 2019, pp. 27-54.

ressaltando assim na publicação do segundo Programa Nacional de Direitos Humanos - PNDH2.

Deste momento em diante, devido as várias discussões dentro dos três poderes políticos, se fez necessário a ampliação desse programa, e então, se fez um terceiro documento, esse sim, mais robusto destacando a transversalidade e inter-ministerialidade de suas diretrizes, de seus objetivos estratégicos e de suas ações programáticas, na perspectiva da universalidade, indivisibilidade e interdependência dos direitos.

O debate público, quero deixar bem claro, em escala nacional, para a elaboração do PNDH-3 coincidiu com os 60 anos da Declaração Universal dos Direitos Humanos e com a realização da $11^{\mathrm{a}}$ Conferência Nacional dos Direitos Humanos $-11^{\mathrm{a}} \mathrm{CNDH}$, sendo convocada por decreto presidencial em abril de 2008 entrou com o Grupo de Trabalho Nacional instituído pela Portaria $n^{\circ} 344$ da SEDH/PR, tinha como tarefa coordenar as atividades preparatórias, formular propostas e orientar as conferências estaduais e distritais. Foram envolvidos representantes de entidades nacionais e movimentos de Direitos Humanos e membros dos Poderes Executivo, Legislativo e Judiciário, do Ministério Público e da Defensoria Pública.

O PNDH-3 está estruturado em seis eixos orientadores, subdivididos em 25 diretrizes, 82 objetivos estratégicos e 521 ações programáticas. Convém destacar nesse programa, como alicerce de sua construção, propostas aprovadas em cerca de 50 conferências nacionais com temáticas realizadas desde 2003 sobre igualdade racial, direitos da mulher, segurança alimentar, cidades, meio ambiente, saúde, educação, juventude, cultura etc.

Existe uma preocupação por parte do ministro Paulo Vannuchi em relação ao comprometimento das diretrizes desenvolvidas a partir dos eixos orientadores. Discorre Vannuchi: ...os compromissos de promoção e proteção dos Direitos Humanos expressos no PNDH-3, estende-se para além da atual administração e devem ser levados em consideração independentemente da orientação política das futuras gestões. A agenda de promoção e proteção dos Direitos Humanos deve transformar-se numa agenda do Estado brasileiro, tendo como fundamentos os compromissos internacionais assumidos pelo país. (PNDH-3, pág.17) 
Artigo original

Hegemonia - Revista Eletrônica do Programa de Mestrado em Direitos Humanos, Cidadania e Violência/Ciência Política do Centro Universitário Unieuro

ISSN: 1809-1261

UNIEURO, Brasília, número 28, Julho a Dezembro de 2019, pp. 27-54.

Ainda podemos destacar no PNDH-3 a sua estrutura nos seguintes eixos orientadores: Interação Democrática, Democracia entre Estado e Sociedade Civil, Desenvolvimento e Direitos Humanos, Universalizar Direitos em um Contexto de Desigualdades; Segurança Pública, Acesso à Justiça e Combate à Violência; Educação e Cultura em Direitos Humanos; Direito à Memória e à Verdade. Compreendendo que todos os agentes públicos e todos os cidadãos são responsáveis pela efetivação dos Direitos Humanos no país, o tema da Integração Democrática entre Estado e Sociedade Civil abre o Programa.

Mostrando ter como compromisso de governo a manutenção, revisão, aperfeiçoamento e ampliação de seus itens formadores, Paulo Vannuchi deixa bem claro que o PNDH-3 apresenta as bases de uma Política de Estado para os Direitos Humanos e ainda estabelece diretrizes, objetivos estratégicos e ações programáticas a serem trilhados nos próximos anos. A definição operacional de sua implementação, com estabelecimento de prazos, será garantida por meio de Planos de Ação a serem construídos a cada dois (2) anos, sendo fixados os recursos orçamentários, as medidas concretas e os órgãos responsáveis por sua execução.

Eixos Orientadores - E suas Definições

I. Interação Democrática entre Estado e Sociedade Civil;

As questões sociais no Brasil começaram a se manifestar a partir dos anos 70, ainda estávamos na ditadura militar e o povo brasileiro já queria se manifestar a respeito das condições sociais em que viviam. Essas iniciativas populares se voltavam para os bairros mais carentes onde as necessidades eram mais gritantes. Os diretos básicos como saúde, transporte, moradia e controle do custo de vida, eram iniciativas automatizadas, buscando conquistas parciais, mas a medida que passavam os anos, foram se caracterizando como movimentos sociais organizados.

Com o avanço da democratização do País, os movimentos sociais multiplicaram-se e alguns deles institucionalizaram-se e passaram a ter expressão política. Os sindicatos e movimentos populares tiveram grande importância no processo de abertura política, onde consequentemente veio a modificação de nossa carta magna a Constituição de 1988, considerada uma constituição cidadã. 
Artigo original

Hegemonia - Revista Eletrônica do Programa de Mestrado em Direitos Humanos, Cidadania e Violência/Ciência Política do Centro Universitário Unieuro

ISSN: 1809-1261

UNIEURO, Brasília, número 28, Julho a Dezembro de 2019, pp. 27-54.

Alguns dos setores mais organizados da sociedade trouxeram reivindicações históricas acumuladas de anos e influenciaram diretamente nas eleições de 2002. O diálogo entre o Estado e a sociedade civil assumiu especial relevo, com a compreensão e preservação do distinto papel de cada um dos segmentos no processo de gestão. Com isso, um novo senário se desenhava no País, onde diversos órgãos do Estado e a sociedade civil trouxeram consigo resultados práticos em termos de políticas públicas e avanço na interlocução de setores do poder público com toda a diversidade social, cultural, étnica e regional caracterizando assim, os maiores movimentos sociais do País.

Nesse sentido, houve um avanço fundamental em relação a compreensão de que os Direitos Humanos constituem condição uma condição de prevalência da dignidade humana, e que devem ser promovidas e protegidas por meio de esforço conjunto do Estado e da sociedade civil. Esse seria então o papel fundamental do Programa Nacional de Direitos Humanos - PNDH-3 para dar continuidade a integração e ao aprimoramento dos mecanismos de participações existentes, bem como criar novos meios de construção e monitoramento das políticas públicas sobre Direitos Humanos no Brasil.

\section{Desenvolvimento e Direitos Humanos;}

Propondo a questão de "desenvolvimento" tema o qual se torna muito difícil de ser definido, mas que apresenta nos dias de hoje um significado amplo quando se trata de garantir a livre determinação dos povos, o reconhecimento de soberania sobre seus recursos e riquezas naturais, respeito pleno a sua identidade cultural e a busca de equidade na distribuição das riquezas.

Durante muito tempo foi utilizado o índice de crescimento econômico que era medido pela variação anual do Produto Interno Bruto - PIB, onde se acreditava que com o aumento de bens e serviços, poderia também possibilitar a distribuição desses produtos por igual satisfazendo assim as necessidades de todas as pessoas. Dessa forma estudos feito pelo governo, mostrou que teria que ser necessário uma nova fórmula para possibilitar esses serviços e produtos atingível em todos os níveis sociais. 
Artigo original

Hegemonia - Revista Eletrônica do Programa de Mestrado em Direitos Humanos, Cidadania e Violência/Ciência Política do Centro Universitário Unieuro

ISSN: 1809-1261

UNIEURO, Brasília, número 28, Julho a Dezembro de 2019, pp. 27-54.

Com base nesses dados, o conceito de "desenvolvimento" foi adotado por ser mais abrangente e refletir, de fato, melhorias nas condições de vida dos brasileiros. A teoria predominante de "desenvolvimento econômico" o define como um processo que faz aumentar as possibilidades de acesso das pessoas a bens e serviços, propiciadas pela capacidade de expansão e das atividades econômicas. O "desenvolvimento" seria medido qualitativa do progresso de economia do País, onde aí, estaria pontuado a situação em que todos os brasileiros tivessem acesso aos bens e produtos produzidos pelo mercado brasileiro.

Pensando dessa maneira, cresce então, a ideia de que são essenciais para o desenvolvimento, as liberdades e os direitos básicos como a alimentação, saúde e educação. Essas liberdades sendo privadas da sociedade, leva não só a escassez de recursos, mas também, as desigualdades inerentes aos mecanismos de distribuição, a ausência de serviços públicos e da assistência do Estado para a expansão das escolhas individuais. Este conceito vem então reconhecer seu caráter pluralista e a tese de que a expansão das liberdades não representa somente um fim, mas uma contínua luta pelos direitos que as convém.

Todo esse procedimento político e social só poderá ser efetivado se houver uma participação da sociedade como protagonista do processo em si, para garantir os direitos nas áreas econômicas, sociais, culturais e ambientais, e incorporando a preocupação com a preservação e a sustentabilidade como eixos estruturantes de proposta renovadas do progresso, tendo como foco a distribuição de riquezas, dos bens e serviços não só, das pessoas, mas também de soberania nacional.

A partir de todo esse processo em debate, vem trazer desafios para conceituação sobre os Direitos Humanos no sentido de incorporar o "desenvolvimento" como exigência fundamental da incorporação das relações entre os direitos econômicos, sociais, culturais e ambientais, buscando garantir o acesso ao trabalho, à saúde, à educação, à alimentação, à vida cultural, à moradia adequada, à previdência, à assistência social e a meio ambiente sustentável.

Alcançar o desenvolvimento com Direitos Humanos é capacitar as pessoas e as comunidades a exercerem a cidadania, com direitos e responsabilidades. Permite ao mesmo tempo incorporaras população brasileira, por meio participativo nas decisões tomadas para garantir a transparência, o desenvolvimento econômico e os mecanismos de propiciam a população brasileira nos seus direitos como cidadão. 
Artigo original

Hegemonia - Revista Eletrônica do Programa de Mestrado em Direitos Humanos, Cidadania e Violência/Ciência Política do Centro Universitário Unieuro

ISSN: $1809-1261$

UNIEURO, Brasília, número 28, Julho a Dezembro de 2019, pp. 27-54.

III. Universalizar Direitos em um Contexto de Desigualdade;

A Declaração Universal dos Direitos Humanos afirma em seu preâmbulo que o "reconbecimento da dignidade inerente a todos os membros da familia bumana e de seus direitos iguais e inalienáveis é o fundamento da liberdade, da justiça e da paz, no Mundo", mas a partir da identificação de ideias divergentes ocorridas no cumprimento da Declaração pelos Estados signatários, verificou-se a necessidade de reconhecer as diversidade e diferenças para a concretização do princípio da igualdade.

No Brasil, porém, os Direitos Humanos tiveram uma posição de destaque nos últimos dez anos e ainda continua. Houve um avanço significativo e decisivo na proteção e promoção dos direitos às diferenças. Mas o peso negativo do passado ainda assombram as mentes atuais.

Podemos observar ainda nos dias de hoje que, o acesso aos direitos fundamentais continua enfrentando barreiras culturais, resquícios de um processo histórico, até secular, marcado por genocídio indígena, pela escravidão e por período ditatoriais, práticas que continuam a ecoar nas leis, comportamento e na realidade social. E podemos observar que nesse eixo o PNDH-3 procura colocar no seu contexto das diretrizes, objetivos e ações grandes avanços conquistados tanto nas políticas de erradicação da miséria e da fome, quanto na preocupação com a moradia e a saúde, dando continuidade e ampliação do acesso a tais políticas.

Os objetivos estratégicos direcionados à promoção da cidadania plena preconiza a universalidade, indivisibilidade e interdependência dos Direitos Humanos, condições para a sua efetivação integral e igualitária. $\mathrm{O}$ acesso aos direitos de registro civil, alimentação adequada, terra e moradia, trabalho decente, educação, participação política, cultura, lazer, esporte e saúde, deve considerar a pessoa humana em suas múltiplas dimensões de ator social e sujeito da cidadania.

As ações programáticas formuladas visam a enfrentar o desafio de eliminar as desigualdades, levando em conta as dimensões de gênero e raça nas políticas públicas, desde 
Artigo original

Hegemonia - Revista Eletrônica do Programa de Mestrado em Direitos Humanos, Cidadania e Violência/Ciência Política do Centro Universitário Unieuro

ISSN: 1809-1261

UNIEURO, Brasília, número 28, Julho a Dezembro de 2019, pp. 27-54.

o planejamento até a sua concretização e avaliação. Há, neste sentido, propostas de criação de indicadores que possam mensurar a implementação progressiva dos direitos.

IV. Segurança Pública, Acesso a justiça e Combate a Violência;

A segurança pública no Brasil sempre foi um tema a ser debatido em todas as esferas das políticas públicas. Isso se deve ao longo período que tivemos de repressão social e também de fechamento dos pensamentos dentro dos órgãos públicos e representantes do governo. As condições históricas, políticas e culturais formavam um bloqueio das ideias para que houvesse um diálogo entre os temas da segurança pública e os Direitos Humanos.

Nos últimos anos podemos observar que esse diálogo começou então a ocorrer por parte da articulação na sociedade civil, onde assumiram o desafio de repensar a segurança pública a partir de diálogos com especialistas na área, policiais e gestores. Por outro lado, começaram então a ser implantadas as primeiras políticas públicas buscando caminhos alternativos na redução do crime e da violência. Surge então o Sistema Único de Segurança Pública - SUSP, modernizando parte das nossas estruturas policiais e a aprovação de novos regimes e leis orgânicas das polícias, formação das "forças de segurança" e o surgimento de novas gerações de policiais.

O Programa Nacional de Segurança Pública com Cidadania - Pronasc e a montagem de uma Rede nacional de Altos Estudos em Segurança Pública - Renaesp ${ }^{4}$, atuam na formação e benefícios dos militares em todos os Estados. Além de obter esses programas, O PNDH-3 aponta para uma ampla reforma do modelo de polícia com participação popular, do Estado, das corporações e coloca uma reformulação do Conselho Nacional de Segurança Pública - Conasp. Contempla a prevenção da violência e da criminalidade como diretriz, ampliando o controle sobre armas de fogo e indicando a necessidade e profissionalização da investigação criminal.

Ainda como diretriz, o programa propõe profunda reforma da Lei de Execução Penal, que introduz garantias fundamentais e novos regramentos para superar as práticas

\footnotetext{
${ }^{4}$ Em funcionamento desde 2007, a Renaesp atende policiais militares, civis, bombeiros e guardas municipais. A Rede é composta por cursos de pós-graduação lato sensu (especialização). As aulas abordam temas como ética, direitos humanos, sociologia e técnica policial.
} 
Artigo original

Hegemonia - Revista Eletrônica do Programa de Mestrado em Direitos Humanos, Cidadania e Violência/Ciência Política do Centro Universitário Unieuro

ISSN: 1809-1261

UNIEURO, Brasília, número 28, Julho a Dezembro de 2019, pp. 27-54.

abusivas. Trata as penas privativas como a última alternativa, propondo a redução da demanda por encarceramento e estimulando novas formas de tratamento dos conflitos. Dessa forma o PNDH-3 apresenta nesse eixo, fundamentalmente, propostas para que o Poder Público se aperfeiçoe no desenvolvimento de políticas públicas de prevenção ao crime e a violência.

V. Educação e Cultura em Direitos Humanos;

Quando de fala em educação e cultura nesse País, podemos ter várias polêmicas nesse contexto, principalmente em se tratando da sociedade mais abastada. É pensando nessas condições que a educação e a cultura em Direitos Humanos visam à formação de nova mentalidade coletiva para o exercício da solidariedade, do respeito às diversidades e da tolerância.

Como processo sistemático e multidimensional que orienta a formação do sujeito de direitos, seu objetivo é combater o preconceito, a discriminação e a violência, promovendo a adoção de novos valores de liberdade, justiça e igualdade. Trata-se de mecanismos que articulam valores ligados a educação com os Direitos Humanos, onde podemos destacar a apreensão de conhecimentos historicamente construídos sobre os Direitos Humanos e a sua relação com os contextos internacional, nacional, regional e local, a afirmação de valores, atitudes e práticas sociais, a formação de consciência cidadã capaz de se fazer se presente nos níveis cognitivo, social, ético e político, o desenvolvimento de processos metodológicos participativos e de construção coletiva, utilizando linguagens e materiais didáticos contextualizados e o fortalecimento de políticas que gerem ações e instrumentos em favor da promoção, da proteção e da defesa dos Direitos Humanos, bem como da reparação das violações.

Existe uma relação entre o PNDH-3 e o Plano Nacional de Educação em Direitos Humanos - PNEDH com referência para a política nacional de Educação e Cultura dos Direitos Humanos, estabelecendo os pilares a serem adotados nos âmbitos nacional, estadual, distrital e municipal. Esse programa reflete o desdobramento em 5 (cinco) grandes áreas: educação básica, fundamental e médio, superior e educação continuada. 
Artigo original

Hegemonia - Revista Eletrônica do Programa de Mestrado em Direitos Humanos, Cidadania e Violência/Ciência Política do Centro Universitário Unieuro

ISSN: 1809-1261

UNIEURO, Brasília, número 28, Julho a Dezembro de 2019, pp. 27-54.

A relação existente entre a Educação, Cultura e os Direitos Humanos, leva todos os setores do governo e das políticas públicas a consolidação de um Estado Democrático, com isso, dá-se o direito de todos os cidadãos brasileiros independentes de cor, sexo, etnia e nível social a proteção do direito à vida e à dignidade, garantindo tratamento igual e o funcionamento de sistemas de Justiça aplicado dignamente.

VI. Direito a Memória e a Verdade

Para se investigar o passado é preciso resgatar sua verdade e trazer à tona seus acontecimentos, suas cicatrizes e histórias que vão lembrar momentos de dor, medo e angústia.

Pensando nessas pessoas o PNDH-3 procurou por meio de buscar por meio de leis o amparo legal dessas famílias e seus desaparecidos, sob uma injustiça regimental do passado. No ano de 1995, depois de muitas discussões entre familiares de desaparecidos e mortos por esse regime pelo Ministério da Justiça e o Poder Legislativo Federal, foi aprovado a Lei de $\mathrm{n}^{\circ}$ 9.140/1995 que conheceu a responsabilidade do Estado brasileiro pela morte de opositores ao regime de 1964.

Em agosto de 2007, em ato coordenado pelo Presidente da República, foi lançado, pela Secretaria Especial dos Direitos Humanos da Presidência da República (SEDH/PR) e pela Comissão Especial sobre Mortos e Desaparecidos Políticos (CEMDP), o livrorelatório "Direito à Memória e à Verdade", onde instaura o registro e o resumo histórico das vítimas da ditadura no Brasil.

Em julho de 2008, o Ministério da Justiça e a Comissão de Anistia promoveram audiência pública sobre "Limites e Possibilidades para a Responsabilização Jurídica dos Agentes Violadores de Direitos Humanos durante o Estado de Exceşão no Brasil', que discutiu a interpretação da Lei de Anistia de 1979 no que se refere à controvérsia jurídica e política envolvendo a prescrição ou imprescritibilidade dos crimes de tortura.

Juntamente com esses projetos e leis podemos citar o Projeto de Lei no 5.228/2009, assinado Presidente da República, o então naquela ocasião, o Sr. Luiz Inácio Lulas da Silva, que introduz avanços democratizantes nas normas reguladoras do direito de acesso a informação ao Arquivo Nacional. 
Artigo original

Hegemonia - Revista Eletrônica do Programa de Mestrado em Direitos Humanos, Cidadania e Violência/Ciência Política do Centro Universitário Unieuro

ISSN: 1809-1261

UNIEURO, Brasília, número 28, Julho a Dezembro de 2019, pp. 27-54.

As ações programáticas deste eixo orientador têm como finalidade assegurar o processamento democrático e republicano de todo esse período da história brasileira, para que se viabilize o desejável sentimento de reconciliação nacional.

\section{Considerações Finais}

Desde a elaboração da Declaração Universal dos Direitos Humanos em 10 de dezembro de 1948, o mundo não foi o mesmo em relação aos seres de todo o planeta. Fundou-se aí o alicerce de uma nova convivência humana e podemos perceber com o passar dos anos, que as cada momento vivemos uma situação diferenciada e ao mesmo tempo, mudanças ocorrem em relação ao comportamento, tratamento e relacionamento entre os seres humanos.

Os Direitos Humanos são orientados pela afirmação do respeito ao outro e pela busca permanente da paz. Isso só pode ser possível se as pessoas se respeitarem mutuamente e se sentirem respeitadas pelos seus Estados como cidadãos e pessoas de bem.

Nós podemos ver no decorrer da história que o Mundo passou e ainda passa, por grande transformação de comportamento humano, seja ele, por questões sociais, religiosas, humanitárias, culturais entre outras. E mesmo assim podemos perceber que os Direitos Humanos ainda se encontram com certas dificuldades de caminhar em determinados Países.

Podemos tomar o Brasil como exemplo, onde a partir da Constituição de 1988, em que pela primeira vez em uma constituição foram relevados direitos ao cidadão brasileiro como realmente se deve ter. Esses direitos forçaram a sociedade a formar grupos comunitários, onde especialmente os setores populares organizados, puderam então, formular ideias e correr atrás de seus direitos.

No ano de 1993, na Conferência de Viena, da ONU, fortalecendo os postulados básicos de universalidade, indivisibilidade e interdependência, recomendou que os Países formulassem e implementassem Programas e Planos Nacionais de Direitos Humanos, foi então que o nosso país entrou definitivamente como País membro do Comitê Internacional de Direitos Humanos. 
Artigo original

Hegemonia - Revista Eletrônica do Programa de Mestrado em Direitos Humanos, Cidadania e Violência/Ciência Política do Centro Universitário Unieuro

ISSN: 1809-1261

UNIEURO, Brasília, número 28, Julho a Dezembro de 2019, pp. 27-54.

Formulando uma Carta Constitucional, o Brasil, era parte integrante do Comitê, ratificando os instrumentos internacionais dos Direitos Humanos, e assim tornando-nos parte do ordenamento nacional. Tendo agora os termos jurídico-políticos, em que constitui em exigência de respeito a suas determinações pelo país.

A Carta Constitucional inclui entre os fundamentos do Estado brasileiro a cidadania e a dignidade da pessoa humana, ainda estabelecendo como objetivo a construção de uma sociedade livre, justa e solidária. Isso nos permite ver que podemos muito progredir enquanto cidadãos, sociedade e políticas públicas.

Como os Direitos Humanos no Brasil é orientado por diretrizes nacionais, e ao mesmo tempo, orientam também a atuação do poder público, foram desenvolvidas a partir de $1996 \mathrm{com}$ o lançamento do Primeiro Programa Nacional de Direitos Humanos (1) o PNDH-1. Com o passar do tempo, vimos que haviam necessidades de se aperfeiçoar essas diretrizes e então no ano de 2002 foi revisado e elaborado o segundo programa, passando a se chamar Programa Nacional dos Direitos Humanos (2) - PNDH-2.

A partir do governo Lula, vai ocorrer vários movimentos a respeito dos Direitos Humanos em todos os segmentos sociais. Dessa forma, o governo abre debates políticos, públicos e de comunidades sociais, alavancando o processo democrático que tanto precisava para deslanchar o programa nacional. Abrindo esses debates em congresso e seminário, o governo possibilita que venham a ter formação de comitês organizadores de classe sociais e então ocorre a reformulação do PNDH-2.

Com a oportunidade de debater assuntos até então se encontravam muito fechados, e pelos embates ocorridos entre os três poderes, ministérios e comitês sociais, agora com maior clareza e organização de pensamentos e colocações de opiniões, surge então a reformulação e ampliação do terceiro e último programa nacional, passando assim a ser o Programa Nacional dos Direitos Humanos(3) - PNDH-3.

Mais bem formulado que os outros dois PNDHs, o PNDH-3 vai apresentar uma estrutura mais complexa e completa em todos os seguimentos públicos e políticos. Passando a ter eixos orientadores, subdivididos em 25 diretrizes, 82 objetivos estratégicos e 521 ações programáticas, onde foram incluídas propostas aprovadas em cerca de 50 conferências nacionais realizadas desde e 2003 sobre igualdade racial, direitos da mulher, segurança alimentar, cidades, meio ambiente, saúde, educação, cultura, juventude, sustentabilidade e justiça social. 
Artigo original

Hegemonia - Revista Eletrônica do Programa de Mestrado em Direitos Humanos, Cidadania e Violência/Ciência Política do Centro Universitário Unieuro

ISSN: 1809-1261

UNIEURO, Brasília, número 28, Julho a Dezembro de 2019, pp. 27-54.

Se colocarmos tudo isso no final de um balanço democrático, podemos perceber que o nosso Programa Nacional de Direitos Humanos, sendo cumprido na sua íntegra, estaríamos entre os maiores Países com equilíbrio humanitário, ou seja, se já temos aqui no Brasil um grande número de imigrantes, penso que poderíamos até cobrir mais de 85\% do território desse imenso País.

\section{REFERÊNCIA BIBLIOGRÁFICA}

BENEVIDES, Maria Victoria. Cidadania e Direitos Humanos. Instituto de Estudos Avançados da Universidade de São Paulo, texto disponível em http://institutoelo.org.br/site/app/webroot/files/publications/4b2cc583e37de38a31983ddb3f7 861d0.pdf, acessado em 05.out.2013.

BRASIL. Constituição da República Federativa do Brasil. Poder Legislativo. Brasília, DF, 1988. Disponível em: http://www.planalto.gov.br/ccivil_03/constituicao/constituicaocompilado.htm. Acesso em: 05.out.2013.

, Decreto $\mathrm{n}^{\circ}$ 1.904, de 13 de maio de 1996 - PNDH 1. Disponível em: portal.mj.gov.br/sedh/pndh/pndh1.pdf - Acesso em: 05.out.2013

Programa Nacional de Direitos Humanos 2, 2001. Disponível em:

portal.mj.gov.br/.../pndh/pndhII/Texto\%20Integral\%20PNDH\%20II.pdf

CARBONARI, Paulo César. Direitos humanos no brasil: Uma leitura da situação em perspectiva. in Coletânea CERIS. Misereor/MNDH/DhESCA Brasil/PAD. Direitos Humanos no Brasil 2: diagnóstico e perspectivas. Coord. Daniel Rech; Enéias da Rosa; Irene Maria dos Santos; Júlia Esther Castro; Maria Elena Rodriguez e Paulo César Carbonari. An 1, Número 1, Rio de Janeiro: Ed. CERIS/Mauad., 2003, p. 20.

MELLO, Celso d. Albuquerque. Curso de Direito Internacional Público. $1^{\circ}$ vol., Freitas Bastos, 4 a ed., 1974, p. 416. 
Artigo original

Hegemonia - Revista Eletrônica do Programa de Mestrado em Direitos Humanos, Cidadania e Violência/Ciência Política do Centro Universitário Unieuro

ISSN: 1809-1261

UNIEURO, Brasília, número 28, Julho a Dezembro de 2019, pp. 27-54.

PEYTRIGNET, Gérard. Direito internacional Humanitário Moderno: fundamentos e Desenvolvimento históricos, Princípios essenciais e Mecanismos de aplicação. Revista do Instituto Brasileiro de Direitos Humanos - IBDH, Na 1, vol. 1, número 1, 1999, ISSN 1677-1419, p. 88

ROCHA, Fernando Luiz Ximenes. A incorporação dos Tratados e Convenções Internacionais de Direitos Humanos no Direito Brasileiro. Revista do Instituto Brasileiro de Direitos Humanos IBDH, Na 1, vol. 1, número 1, 1999, ISSN 1677-1419, p. 100

TRINDADE, Antônio Augusto Cançado. A Proteção Internacional dos Direitos Humanos: Fundamentos e Instrumentos Básicos. Saraiva, 1991.

A Evolução da Proteção dos Direitos Humanos e o Papel do Brasil, in: A Proteção dos Direitos Humanos nos Planos Nacional e Internacional: Perspectivas Brasileiras. IIBH, 1992, p. 34. 